\title{
The role of tasting in the purchasing process
}

\author{
Roos Oomen \\ Independent researcher, Amsterdamsestraatweg 699BA, Utrecht, The Netherlands
}

\begin{abstract}
In the Netherlands, it is forbidden by law to taste and sell wine in the same room, even if the buyer only places an order for delivery and no actual exchange of money and wine takes place, with the exception of licensed liquor stores. Wine traders, tastings and events are disadvantaged by this law. Wine tastings where consumers can buy or order wine are officially forbidden, even in a licensed liquor shop. The law makes no distinction between the act of "tasting" and the act of "drinking" wine. This raises the question whether tasting equals drinking or not, and what the role of tasting entails in the process of purchasing and consuming wine.

This seems even more relevant considering the current trend that consumers not only want to buy a product, but have a complete "experience". They want to feel the product, and in the case of wine they want to smell and taste it. In addition, wine lovers do not just want to purchase a wine of good quality, but they also want to tell the story of the wine and interpret the flavour. And what better way of doing that than to let the consumer taste the wine with guidance of the seller, who knows the wine and its flavour and story?

Purpose - The purpose of this paper is to examine the role of tasting in the process of purchasing and consuming wine. The study seeks to establish whether tasting should be considered part of the purchase process or whether it is part of the consumption. Furthermore, it is exploring the role tasting has in the process of purchasing and consuming wine and the possible risks and benefits of tasting for the seller. The conclusions can be used to advise the Dutch government concerning their policy regarding alcoholic beverages.

Approach - This paper is an exploratory study. The data are collected through literature review in the fields of wine research and marketing and consumer behaviour. It combines relevant theories in the aforementioned fields to define and re-evaluate available data and common assumptions in order to generate new insights.

Findings - Wine tasting can be defined as "the looking at, smelling, and tasting of wine, in order to assess the quality of the wine", and is part of the purchase process. Tasting is a key aspect of the purchasing decision for a majority of wine buyers. The role of tasting in this process is mostly risk-reducing due to the information and reassurance the tasting provides. Possible benefits for sellers such as retailers and restaurant owners are that consumers perceive less risk and therefore are more likely to spend more money. Other benefits include that consumers are more likely to select a wine that they are unfamiliar with, and that they are more receptive to the advice of the seller.

Research implications - The findings of this research suggest that wine tasting may have a more important role in the purchase process than many may realize. The understanding of these findings could ultimately lead to more sampling in the wine shop, and it could become as important to the consumer as it is for shoppers to try on new clothes before buying them. Although findings are tentative due to the exploratory nature of this study, they may provide useful insights to the Dutch government, and the wine and restaurant industry, who would benefit from further (field) research.

Value - This study is of value to the Dutch government and the wine lobby, because it demonstrates the difference between wine tasting and drinking. It also has value for restaurant owners, the wine industry, and the academic world, because it highlights an important aspect of consumer behaviour with regard to wine purchases.
\end{abstract}

\section{Introduction}

In the Netherlands, it is forbidden by law to offer tasting and to sell wine in the same room, even if the buyer only places an order for delivery and no actual exchange of money and wine takes place, with the exception of licensed liquor stores. Wine traders and supermarkets are disadvantaged by this law, because they cannot offer their customers tasting of wine. Wine tastings and wine events where consumers can buy or order wine are officially forbidden, even if they take place in a licensed liquor shop.

Above-mentioned is the case because Dutch law makes no distinction between the act of "tasting" and the act of "drinking" wine. There exists little information about this distinction and there are no clear definitions on the subject.
This could easily lead to the conclusion that there is no distinctive difference between tasting and drinking. It can also lead to the conclusion that tasting is not important when purchasing wine and has no value to both the consumer and the seller.

The role of tasting does seem relevant considering our economy has progressed into an experience economy [1]. This means consumers today do not only want to buy a product, but want to have a complete "experience". They want to feel the product, and in the case of wine they want to smell and taste it.

In addition, it also means that wine lovers do not just want to purchase a wine of good quality, but they also want to tell the story of the wine and interpret the flavour. And what better way of doing that than to offer the 
consumer tastings with guidance of the seller, who knows its flavour and story and can put it into context? The sellers knowledge combined with the actual sensory experience of tasting make it a complete experience for the consumer.

When the word tasting and all its context is extensively considered, two elements can be discovered. The first element is physical: experiencing the flavour and texture of the product. The second element is more abstract: assessing the products quality. Both elements are linked to sampling, buying and/or consuming the product, but in different ways. The physical element could be considered part of consumption because it is the experience one has when consuming the product. The abstract element seems more part of the sampling or early stages of the buying process, because the assessment of the product usually takes place before making a buying decision.

All this raises the question whether tasting equals drinking or not, and what the role of tasting entails in the process of purchasing and consuming wine.

To answer this question first had to be determined how to define the terms "tasting", "consuming" and "purchasing" of wine and the purposes of those activities. Furthermore, the role of tasting in the process of purchasing and consuming wine, and the possible risks and benefits of tasting for the seller were explored. The conclusions can be used to advise the Dutch government concerning their policy concerning alcoholic beverages.

A Dutch experiment in organic food shops and supermarkets showed that offering tastings increased sales of biological products with ten percent at that same day. Five percent of that sale increase lasts the following two weeks, and two percent lasts the following month [2]. This suggests that regular tastings increases sales, perhaps even permanently.

The objective of this study was to determine the role of tasting in the process that extends from the moment the consumer first thinks about purchasing wine to the consumption of the purchased wine by reviewing existing literature.

\section{Methodology}

This paper is the result of an exploratory study. The data was collected through literature review in the fields of wine research and marketing, and consumer behaviour. Literature was collected by exploring books, studies and journals on the subject of tasting, consuming and purchasing in general, and tasting, consuming and purchasing of wine specifically.

Theories in the aforementioned fields were assessed to determine whether they were relevant to the subject of this study. After careful consideration the relevant theories were combined to define and re-evaluate available data and common assumptions in order to generate new insights regarding the role of tasting in the purchasing process.

\section{Results}

When answering the question of what the role of tasting entails in the process of purchasing and consuming wine, the first thing that must be explored is its significance. The significance of tasting wine indicates the direction of the research.

To examine the possible roles of tasting, the exact definitions of the terms wine tasting, consumption and purchasing must be set. These definitions are formed by consulting several sources to review the terms from multiple angels and perspectives. Together they form a strong indication that leads to the definition as used in this paper.

Finally, insight in the purchase process and the purchase decision is required. These insights lead to the determination of the role of tasting. This chapter shows relevant results in the research that provide insight in above-mentioned subjects.

\subsection{Significance of tasting}

Several researches through the years report that wine tasting is an important aspect in regard to purchasing. Mitchell \& Greatorex [3] found that consumers seek reassurance through in-store wine tastings, to reduce their financial risk and increase their wine knowledge. Similarly, Halstead [4] suggests that wine companies should understand the importance of in-store tasting, because his study suggests that sampling has considerable influence on consumer purchase decisions. Likewise, Goodman, Lockshin, \& Cohen [5] identify the tasting of a wine previously to the purchase, either at home or instore, as the most important influencer on consumers who are purchasing wine in retail stores in Australia, the UK, Germany, China and Israel.

How important it is exactly, is demonstrated in the research of Szolnoki, Hoffmann \& Herrmann [6] on the influence of verbal and non-verbal information on the decision of the consumer. Their study shows that the influence of the perceived taste on the purchase decision is extensive, namely $59.1 \%$ (see Fig. 1 ).

The reason it is such a significant factor for the consumer is perhaps because flavour is also the greatest perceived risk, according to the research of Mitchell and Greatorex [3]. They also determine that there are many uncertainties for most consumers in the purchase process of wine. The most important strategy to reduce these

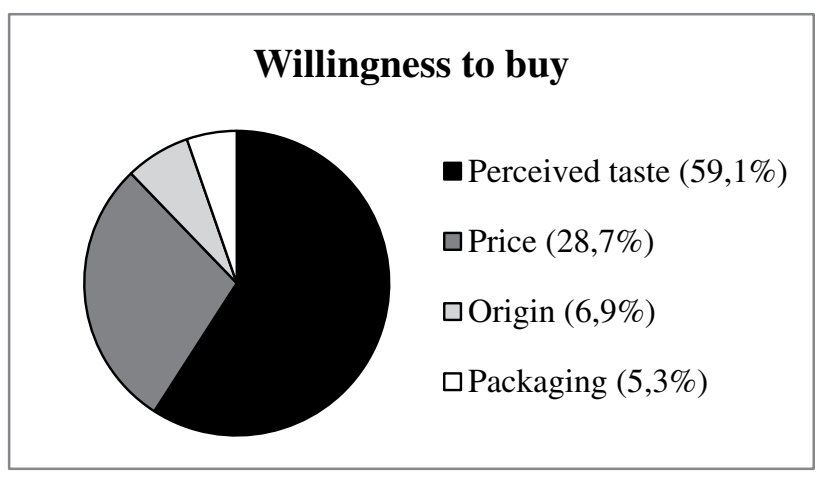

Figure 1. Willingness to buy [6]. 
uncertainties or even to eliminate them is an opportunity to taste the wine.

\subsection{Definition of wine tasting}

\subsubsection{Dictionary}

The Oxford dictionaries [7] define wine tasting as:

The action of judging the quality of wine by tasting it.

\subsubsection{Law}

The state of California recently introduced the "Sip and Spit" law. This law states that students Oenology who are younger than 21 years old, can taste wines when they spit it out. Drinking of alcoholic beverages on the other hand is forbidden by law. Tasting is defined as drawing an alcoholic beverage into the mouth, but does not include swallowing or otherwise consuming the alcoholic beverage. This means a distinction is made between the act of tasting and the act of consuming [7,8].

\subsubsection{Oenology}

Oenologists Ribéreau-Gayon and Blouin [9] defined wine tasting as carefully tasting a product to appreciate the quality; submit it to our senses, especially taste and smell; trying to get acquainted to the wine by searching for its different faults and different qualities and expressing them in words. Is to study, analyse, describe, assess, classify.

In Goût du vin, standard work in the field of wine tasting, renowned oenologist Émile Peynaud [10] describes the purpose of wine tasting as the assessment of the quality by looking at the various faults, qualities and expressions. Tasting is a means to better understand the wine.

\subsubsection{Wine books}

Dutch wine academic and author Albert Holtzappel [11] distinguishes seven types of wine tasting, namely analytical, qualifying, industrial, commercial, ranking, recognizing and descriptive wine tasting. These differentiate in the purpose for which the wine is tasted. The common factor amongst these types is that they do not focus on the joy or delight of drinking wine, but on the acquisition of knowledge by obtaining an objective taste of the wine.

In the Wine Course of the Académie du Vin [12] wine tasting is divided into two types: technical and hedonic tasting. The purpose of technical tasting is the assessment of the wine from a commercial point of view. Hedonic tasting aims to determine the extent of the joy drinking the wine offers. Both types of tasting overlap and complement each other. They lead to an intelligent purchase.

\subsubsection{Traditions}

Written and unwritten rules in the wine tasting dictate that a small amount of approximately $25-50 \mathrm{ml}$ is poured and the taster spits the wine out after having tasted in order to maintain sober and to least effect the wine tasted afterwards. The taster follows the stages of looking, smelling and tasting, and often assesses the wine based on scores and/or test form, possibly using a flavour wheel or aroma box [10-14].

\subsubsection{Definition}

In all definitions above the objective of wine tasting is identified as the assessment of the quality of that wine. In this paper, wine tasting is therefore defined as "seeing, smelling and tasting of wine, aiming to assess the quality of the wine."

\subsection{Definition of consumption}

\subsubsection{Dictionary}

The Oxford dictionaries [7] define consumption as:

1) The act of using energy, food or materials;

2) The act of buying and using products.

The Oxford dictionaries [7] define consume as:

1) Eat, drink, or ingest (food or drink);

2) Buy (goods or services).

In the first meaning drink would apply to wine consumption, therefore the definition for drink is also needed to be complete. Drink is defined as: Take (a liquid) into the mouth and swallow.

\subsubsection{Definition}

In this study consumption is viewed separate from purchase, therefore the definition which suits best and will be used in this paper is: "eating, drinking, or digesting (food or drink)".

\subsection{Definition of purchasing}

\subsubsection{Dictionary}

The Oxford dictionaries [7] define purchase as:

The act or process of buying something.

\subsubsection{Marketing}

Marketing pioneer Edward K. Strong [15] describes the classic marketing model AIDA that is still commonly used in the field of marketing today. It divides the purchase process into four stages: Attention, Interest, Desire and Action, which form the acronym AIDA. The consumer undergoes for each purchase the described stages in this particular order.
A - Attention
I - Interest
to draw attention to the product
D - Desire
to arouse the interest in the product
there is a desire, interest, wish and the decision to own the product
A - Action a call to the action to purchase.

These stages together form the total purchase process. The aim of this study is to identify the role of tasting in this process. Sampling of the product can be perceived as an attempt to influence the purchase decision, in one or more of the AIDA stages. In order to identify this role a more 
detailed examination of the influences on the purchase decision is required.

\subsubsection{Definition}

In this study purchase is defined as: "as the sequence of the stages Attention, Interest, Desire and Action that lead to buying a product or service."

\subsection{Purchase process}

Like the definition shows, the purchase process is divided into four stages: Attention, Interest, Desire en Action. These stages together form the total purchase process. The aim of this study is to identify the role of tasting in this process. Sampling of the product can be perceived as an attempt to influence the purchase decision, in one or more of the AIDA stages. Identifying whether this is the role of tasting requires a more detailed examination of the influences on the purchase decision.

\subsection{Purchase decision}

Consumer purchase decisions can be influenced by a variety of aspects, but all those aspects can be classified in two different effects categories. The factors that influence the ratio, the knowledge of the product or brand, cause the cognitive effect. The factors that influence the emotion, the personal preferences for products or brands, cause the affective effect. Consideration of the cognitive and affective aspects in the conative stage, leads the consumer to make a purchase decision [16-18].

The complexity and variety of wine as a product causes the consumer to perceive a high level of risk in the purchase process [19]. Wine blogger Rebecca Gibb [20] discusses that diversity and complexity of wine can be perceived by consumers as both attractive and intimidating, depending on their background. She argues that there is a large group of millions of consumers who find the assortment in supermarkets intimidating, are being debilitated or even tyrannized by choice.

The most important types of risks consumers perceive when purchasing wine are the functional, social, financial and physical risks [3]. Functional risks revolve around the flavour of the wine, social risks revolve around approval of others, and financial risks revolve around the wine price/ quality ratio. These three risks fall within the scope of this study. Physical risks revolve around the physical consequences of drinking the wine, such as a hangover. This risk cannot be reduced by tasting the wine upfront and will therefore be disregarded in this study.

\subsection{Risk-reduction strategies}

As a coping mechanism consumers utilize many different risk-reduction strategies to lessen the perceived risk. All these various risk-reduction strategies are condensed by Schiffman \& Kanuk [21] into 6 categories of general strategies consumers use in general to reduce perceived risk during a purchase:

1) Information seeking;

2) Loyalty to brands;
3) Buying a well-known brand;

4) Trusting the (reputable) retailer;

5) Price;

6) Seeking reassurance.

Mitchell and Geatorex [3] identified the three most important factors that cause consumers to experience risk-reduction when purchasing wine:

1) Opportunity to taste the wine

2) Personal recommendations from others

3) Free samples.

Both factors 1 and 3 involve tasting, either in-store or elsewhere, and are therefore relevant to this study. These strategies both fall in the category Information seeking, as well as the category Seeking reassurance of the risk-reduction strategies. For wine buyers these strategies seem to be the most reassuring, and are therefore very important in the purchase decision.

\section{Discussion}

The most important conclusion of this exploratory research is that tasting is evidently part of the purchase process, and not of the consumption. The research shows that tasting is not just any part of the purchase process, but a key aspect of the wine purchasing decision for a majority of wine buyers. Tasting suits present-day trends and has economic significant value, on account of the increase of turnover and sales volume it causes.

The role of tasting in this process is mostly riskreducing due to the information and reassurance the tasting provides. Provided information about the product is an important aspect in the wine purchase decision, as the three most important risk-reduction factors are all a form of information seeking. Tasting is the most effective riskreduction strategy when it comes to wine purchase.

Information, such as flavour and texture, is causing an increase of knowledge about the product, and therefore it is part of the cognitive stage of the purchase process. This is one of the stages leading up to the purchase decision. This means that offering tasting can alter the purchase decisions made by consumers.

The findings of this research suggest that wine tasting may have a more important role in the purchase process than many may realize. The understanding of these findings could ultimately lead to more sampling in the wine shop, and it could become as important to the consumer as it is for shoppers to try on new clothes before buying them. Although findings are tentative due to the exploratory nature of this study, they may provide useful insights to the Dutch government, and the wine and restaurant industry, who would benefit from further (field) research. This study was merely a first impression of the subject to recapitulate and compile existing data and investigate possible gaps with significance for further research.

Taken into consideration that tasting has economic significance, this study is of value to the Dutch government and the wine lobby, because it demonstrates the difference between wine tasting and drinking. It also has value for restaurant owners, the wine industry, and the academic world, because it highlights an important aspect of consumer behaviour with regard to wine purchases. 
Possible benefits for sellers such as retailers and restaurant owners are that consumers perceive less risk and therefore are more likely to spend more money. Other benefits include that consumers are more likely to select a wine that they are unfamiliar with, and that they are more receptive to the advice of the seller. The retail and hospitality business can profit from that by having more satisfied customers that feel well assisted and by selling their stock more effectively or selling more wines with a large margin of profit.

\section{References}

[1] Gilmore, J.H. and Pine, J.B. The Experience Economy. s.l. : Harvard Business School Publishing, (1999).

[2] Schlaman, M. and van Boxtel, G. Handboek Directe Verkoop van boerderijproducten. [http:// www . landco.nl/uploads/handboek_ directe_verkoop_van_boerderijproducten. pdf Online] (2008).

[3] Mitchel, V.W. and Geatorex, M. Risk reduction strategies used in the purchase of wine in the UK. International Journal of Wine Marketing. 1 No. 2, (1989), pp. 31-46.

[4] Halstead, L. How do consumers select wine? Factors that affect the purchase decision making process in the wine category. Nottingham : Paper presented at the Annual Academy of Marketing, [http: //www . researchgate. net/publication/253007219_How_do_Consumers_ Select_Wine_Factors_that_Affect_the_Pürchase_Decision_Making_ Process_in_the_wine_Category Online] (2002).

[5] Goodman, S., Lockshin, L. and Cohen, E. Influencers of consumer choice - comparing international markets. (2007), Wine Industry Journal 22(3), pp. 91-95.

[6] Szolnoki, G., Hoffmann, D. and Herrmann, R. The influence of verbal and non-verbal information on the consumer decision. Geisenheim \& Giessen, Germany: s.n., (2008).

[7] Oxford University. Oxford Dictionaries. [http: // www. oxforddictionaries. com/ Online].

[8] The Guardian. California Sip And Spit Wine Bill. The Guardian. [http://www. theguardian. $\mathrm{com} /$ world/2014/jun/26/californiasip-and-spit-wine-bill Online] June 26, (2014).

[9] California State. AB-1989 Underage drinkers: students in winemaking and brewery science programs.
California Legislative Information. [http:// leginfo.legislature.ca.gov/ faces/billNavClient.xhtml?bill $i d=201320140$ OB1989. Online] July 21, (2014).

[10] Peynaud, E. and Blouin, J. Le goût du vin. Paris : Dunod, (2013).

[11] Peynaud, E. Goût du Vin. Paris : Dunod, (1980).

[12] Holtzappel, A. Dat is wijnproeven (That is wine tasting). Utrecht: Het Spectrum, (1986).

[13] Spurrier, S. and Dovaz, M. Wine Course. s.l.: Century Publishing, (1994).

[14] Klosse, P. Het Proefboek (The Tasting Book). Baarn: Trion Uitgevers, (2009).

[15] Stichting Vakbekwaamheid Horeca (Foundation Professional Competence Hospitality). Proeven en beoordelen (Tasting and assessing). Passie voor Horeca (Passion for Hospitality). [passie. horeca.nl/fav/par $4 \% 20$ proeven 20 en $\%$ obeoordelen.pdf Online] February 2, 2015.

[16] Strong, E.K. Theories of Selling. Journal of Applied Psychology. 9, (1925), pp. 75-86.

[17] Pieters, R.G.M. and van Raaij, W.F. De werking van reclame. Leiden: Stenfert Kroese, (1992).

[18] Molenaar, C.N.A. Het consumenten koopproces als basis voor aankopen (The consumer buying process as base for purchases). [htt $\mathrm{p}: / / \mathrm{www}$. vlehan.nl/PDF/Consumenten_koopproces_Molenaar.pdf Online] (2006).

[19] Stichting Vakbekwaamheid Horeca (Foundation Professional Competence Hospitality). Consumentengedrag (Consumer behaviour). Passie voor horeca (Passion for Hospitality). [http: / / passie.horeca.nl/content/18649/ Consumentengedrag.html Online] February 2, (2015)

[20] Lacey, S., Bruwer, J. and Li, E. The role of perceived risk in wine purchase decisions in restaurants. [http://papers.ssrn.com/sol3/ papers.cfm?abstract id=2226249 Online] International Journal of Wine Marketing. (2007).

[21] Gibb, R. Wine and the Paradox of Choice. Wine Searcher. [http://www.wine-searcher. $\mathrm{com} / \mathrm{m} / 2015 / 03 / \mathrm{wine}-$ and-the-paradox-of-choice Online] March 19, (2015).

[22] Schiffman, L.G. and Kanuk, L.L. Consumer Behaviour. Englewood Cliffs: Prentice Hall International, (2006). 